\title{
ACTIVIDAD FITOTÓXICA DEL FILTRAdO CRUDO DE COLLETOTRICHUM GLOEOSPORIOIDES EN CARDAMOMO (ELETTARIA CARDAMOMUM)
}

\author{
SANDRA S. Arango ${ }^{1}$ \\ RODRIGO HOYOS ${ }^{2}$ \\ LuCíA AFANDOR ${ }^{3}$
}

\section{Resumen}

Colletotrichum gloeosporioides es una especie de hongo fitopatógeno de gran importancia, especialmente en las regiones tropicales y sub-tropicales. En Colombia es el agente causal de antracnosis en cardamomo. Se realizaron diferentes experimentos dirigidos a evaluar la actividad fitotóxica del filtrado crudo del hongo en hojas y vitroplantas de cardamomo para demostrar la presencia de compuestos fitotóxicos involucrados en el proceso patogenicidad. Sobre hojas de cardamomo se evaluó la fitotoxicidad de los filtrados obtenidos a partir del cultivo de 4 aislamientos C. gloeosporioides con diferentes condiciones de crecimiento (luz día vs. oscuridad, y medio agitado a $110 \mathrm{rpm}$ vs. sin agitación) y por períodos de fermentación cada uno de 7, 14, 21, 28 días. Encontrándose una mayor actividad fitotóxica en cultivos que crecieron con luz día y más de 21 días de fermentación. Se evalúo la termoestabilidad de los compuestos fitotóxicos del filtrado, sometiéndolos a temperaturas de $25^{\circ} \mathrm{C}, 40^{\circ} \mathrm{C}, 100^{\circ} \mathrm{C}$ y $120^{\circ} \mathrm{C}$, encontrándose que éstos mantienen su actividad fitotóxica después de ser expuestos a estas temperaturas. Se demostró la fitotoxicidad del filtrado en vitroplantas, al exponer 2 grupos de 150 plántulas a concentra-

\footnotetext{
1 Docente investigador, Instituto Tecnológico Metropolitano, sandraarango@itm.edu.co

2 Docente, Universidad Nacional de Colombia, rhoyos@unalmed.edu.co

3 Docente, Universidad Nacional de Colombia, lafanado@unalmed.edu.co
} 
ciones al $50 \%$ y $90 \%$ de éste, evidenciándose daño y mortalidad de éstas en relación a las vitroplantas control.

\section{Palabras clave}

Colletotrichum, Antracnosis, Cardamomo, Fitotoxicidad, Filtrado Crudo.

\section{Abstract}

Colletotrichum gloeosporioides is one of the most important phytopatogen fungi specie in the world, especially in the tropical and subtropical regions. In Colombia it is the causal agent of antracnosis in cardamom plants. Different experiments were done in order to evaluate the phytotoxic activity of the crude filtrate on cardamom leaves and vitroplants, and also to demonstrate the presence of phytotoxic compounds which are involved in the patogenical process. It was evaluated, on cardamom leaves, the phytotoxic activity of the crude filtrate that was obtained from the culture of four C. gloeosporioides isolations. These cultures were done under different growth conditions (light day vs. darkness and agitated culture at 110r.p.m. vs. non agitated cultures) and under different fermentation periods ( $7,14,21,28$ days). It was observed a major phytotoxic activity in cultures that grew up under light day conditions and with a fermentation period superior to 21 days. The filtrate phytotoxicity compounds thermostability was evaluated at different temperatures $\left(25^{\circ} \mathrm{C}, 40^{\circ} \mathrm{C}, 100^{\circ} \mathrm{C}\right.$ and $\left.120^{\circ} \mathrm{C}\right)$ and it was found that these components kept their phytotoxic activity even after being exposed to such temperatures. It was demonstrated the existence of phytotoxic activity of the filtrate on vitroplants when two groups of 150 plants (seedling) each were exposed to concentrations of it of $50 \%$ and $90 \%$ respectively; damage and mortality of these vitroplant in comparison with the control (vitroplants) were shown and found.

\section{Keywords}

Colletotrichum, Antrhacnose, Cardamomo, phytotoxicity, Crude fíltrate. 


\section{INTRODUCCIÓN}

La antracnosis es una de las enfermedades de mayor incidencia en el cultivo del cardamomo -Elettaria cardamomum. Esta patología es causada por hongos de la especie Colletotrichum gloeosporioides (Penz.) Penz \& Sacc. (Jaramillo \& Herrera, 1995; Suseela et al., 1988; Ravindran, 2003; Thomas \& Suseela, 2003). La enfermedad se manifiesta con manchas circulares en espigas, espiguillas y granos, es altamente limitante y genera gran impacto en los cultivos (Tamayo, 2003). Se ha reportado su relación con otra enfermedad llamada "Chental", la cual se manifiesta en lesiones en hojas jóvenes, generando una reducción en la capacidad de captar la luz solar (Bailey, 1992; Ravindran, 2003).

Las interacciones que ocurren entre el patógeno y la planta son complejas, y la importancia de las toxinas producidas por el patógeno en el desarrollo de la enfermedad está demostrada. El término fitotoxina se refiere a cualquier producto del patógeno que es dañino a la planta hospedera, el cual puede ser de tipo proteico o ser un compuesto de bajo peso molecular. Las fitotoxinas tienen dos propiedades importantes: i) Son activas a muy bajas concentraciones y ii) son móviles dentro de la planta, y por lo tanto pueden actuar a distancia del sitio de infección (Yoder, 1998; Svabova \& Lebeda, 2005).

La producción in vitro de fitotoxinas en medios de cultivos ha sido reportada para diferentes especies de hongos (Van den Bulk, 1991; Mathew et al. 2009) y la importancia de los filtrados de sus cultivos está siendo ampliamente estudiada, ya que se ha demostrado que en estos se encuentran diferentes compuestos que producen sintomatología en las plantas (Jayasankar et al., 1999), la mayoría son toxinas no-selectivas de hospedero, que actúan en diferentes procesos fisiológicos de las plantas (Yoder \& Turgeon, 1985; Svabova \& Lebeda, 2005).

Existen referencias que demuestran que metabolitos fitotóxicos producidos en medios de cultivos de especies de Colletotrichum, inducen en plantas síntomas similares a los que produciría el 
patógeno mismo. Algunas de estas toxinas se han utilizado para selección de resistencia y se han demostrado que tienen un papel importante en la patogénesis. (Amusa, 2001; García-Pajón \& Collado, 2003; Theerthagiri et al. 2008). En el filtrado del cultivo de Colletotrichum, se han encontrado sustancias fitotóxicas que interfieren con los mecanismos subcelulares y se sugiere que poseen actividad mutagénica (Jayasankar et al., 1998). También, se encuentran diversas enzimas que pueden degradar paredes celulares, macerar tejidos y alterar la permeabilidad de las células de la planta causando pérdida de la integridad foliar (Duke et al., 1992; Levi et al., 2007; Theerthagiri et al., 2008). Los metabolitos producidos por esta especie son de diferente tipo, entre ellos se encuentran; diterpenos como colletotricina A, B y C (Gohbara et al., 1978); taxol (Gangadevi, 2008); lpoliaminoacidos como las aspergillomarasmina A y B (Ballio et al., 1969) y pironas, como las colletopironas (Gohbara et al., 1976). La determinación de la actividad fitotóxica de un filtrado depende de la inducción parcial o completa de los síntomas en hospederos sanos inoculados, según Jayasankar (1999).

Se evaluó la fitotoxicidad de filtrados de cultivos Colletotrichum gloesporiodes con diferentes condiciones de crecimiento y su relación con la actividad fitotóxica sobre hojas y plántulas de cardamomo. Se demostró que la luz, tiempo de fermentación y aislamiento utilizado tienen efecto sobre la actividad fitotóxica de los filtrados y que éstos mantienen su actividad después de ser sometidos a temperaturas de $40^{\circ} \mathrm{C}, 100^{\circ} \mathrm{C}$ y $120^{\circ} \mathrm{C}$.

\section{Metodología}

\subsection{Material biológico}

Se utilizó el clon de cardamomo M5 del laboratorio de Cultivos de Tejido Vegetales de la Universidad Nacional de Colombia, el cual fue desarrollado a partir de un explante de una plantación del municipio de Jericó (Antioquia). Los aislados del C. gloeospo- 
rioides se obtuvieron de frutos con síntomas típicos de antracnosis provenientes de diferentes zonas de la misma plantación.

\subsection{Establecimiento de cultivos in vitro de cardamomo para el estudio}

Las vitroplantas de cardamomo se micropropagaron en un medio de cultivo con sales y vitaminas completos de Murashige y Skoog (1962) complementadas con: 0,5 mg/l de Piridoxina y de Ácido Nicotínico, 2,0 mg/l de Glicina, $1 \mathrm{mg} / \mathrm{l}$ de AIA, $0,7 \mathrm{mg} / \mathrm{l}$ de BAP, $20 \mathrm{~g} / \mathrm{L}$ de Sacarosa y se ajustó el pH a 5,6 \pm 1 . Los brotes se subcultivaron cada 20 a 30 días a medio fresco.

\subsection{Obtención de cultivos monoespóricos del hongo}

A partir de cultivos del hongo esporulados y purificados se preparó una suspensión acuosa de esporas, la cual se esparció sobre una superficie de medio agar-agua y se incubó a temperatura ambiente por 12 horas hasta la germinación de esporas. Las cuales se sembraron en medio de cultivo PDA acidificado, colocando 9 esporas por caja, los cultivos monospóricos resultantes fueron almacenados en trozos de papel de filtro de $0,5 \mathrm{~cm}^{2}$ y mantenidos $4^{\circ} \mathrm{C}$, siguiendo la metología de Osorio (2001).

\subsection{Evaluación de la patogenicidad de los cultivos monospóricos de $\mathbf{C}$ gloeosporioides en frutos y plántulas de cardamomo}

Con los cultivos monospóricos de C. gloeosporioides se prepararon soluciones a una concentración aproximada de 3,4 x $10^{6}$ esporas $/ \mathrm{ml}$, con las cuales se infectaron 25 frutos de plantas sanas del campo y 10 plántulas del clon de estudio en invernadero, para inducir sintomatología característica (postulado de Koch“s). Se utilizó un Diseño Completamente al Azar. Segmentos de tejido infectado obtenido, se sembraron en agar PDA para comprobar crecimiento del hongo. 


\subsection{Evaluación de condiciones de cultivo del hongo para la obtención del filltrado crudo del hongo}

Se tomaron cuatro aislamientos monospóricos, los cuales se reactivaron en agar $\mathrm{PDA}$, y se incubaron a temperatura ambiente $\left( \pm 27^{\circ} \mathrm{C}\right)$, pasados 12 días se cortaron 4 discos de micelio de 0,5 $\mathrm{cm}$ de diámetro, los cuales se inocularon en $100 \mathrm{ml}$ de medio líquido (agua destilada con $4.4 \mathrm{gm} / \mathrm{l}$ de MS complementado, $20 \%$ de sacarosa). Para cada uno de los aislamientos se evaluaron las siguientes condiciones de fermentación: crecimiento de hongo con luz día con y sin agitación (110 rpm), y crecimiento en oscuridad con y sin agitación (110 rpm) y cada uno de las fermentaciones se incubaron por 7, 14, 21 y 28 días, para un total de 64 tratamientos.

Todas las fermentaciones se mantuvieron a una temperatura de $25 \pm 2^{\circ} \mathrm{C}$. Para la obtención de los filtrados los cultivos se filtraron a través de papel Whatman \#1 y posteriormente por una membrana millipore con un diámetro de $0,20 \mu$, con el fin de eliminar la presencia de cualquier estructura (espora o micelio) del hongo. De cada uno de los filtrados se adicionaron $5 \mathrm{ml}$ a 2 cajas de petri, cada una de las cuales contenía 10 hojas del clon M5 de cardamomo (in vitro). Los controles negativos se inocularon con agua destilada y estéril y con medio de crecimiento del hongo. Después de 6 días se realizó la evaluación, observando cambio en el color del tejido, lo cual representa el efecto fitotóxico del filtrado.

\subsection{Evaluación de la termoestabilidad de los filltrados}

Se tomaron 4 erlemeyer, cada uno con $150 \mathrm{ml}$ de medio líquido (Agua destilada con 4,4 gm/l de MS complementado, y 20\% de sacarosa), los cuales se inocularon con 6 discos de micelio de 0.5 $\mathrm{cm}$ de diámetro. Las fermentaciones se dejaron por 21 días, en condiciones de luz día y sin agitación, se esterilizaron por filtración a través membranas de $0,20 \mu \mathrm{m}$. La primera muestra de $150 \mathrm{ml}$ se concentraron a $40^{\circ} \mathrm{C}$ por 5 horas y nuevamente fue restituido su volumen inicial con agua estéril, la segunda muestra de $150 \mathrm{ml}$ se concentraron a $100^{\circ} \mathrm{C}$ por 5 horas y posteriormente fue restituido su volumen inicial con agua estéril. 
La tercera muestra de $150 \mathrm{ml}$ se esterilizó en autoclave a $120^{\circ} \mathrm{C}$ por 20 minutos a una presión de 20 lb y la cuarta muestra de $150 \mathrm{ml}$ se mantuvieron a una temperatura de $25 \pm 2^{\circ} \mathrm{C}$. La fitotoxicidad de los filtrados se evaluó sobre 4 segmentos de hojas cardamomo clon M5, cada uno se inoculó con 4 gotas de $10 \mu \mathrm{l}$ y fueron mantenidos en una caja de petri y se realizaron 20 repeticiones de este tratamiento, pasados 5 días se observó la presencia de cambios en la coloración en los segmentos de hojas. De igual forma se evaluó sobre frutos de cardamomo que provenían del campo, a los cuales se les realizó una desinfección previa, inoculándose 20 frutos por tratamiento.

\subsection{Evaluación de toxicidad de los filtrados sobre plántulas in vitro de cardamomo}

Se inocularon con 10 discos de micelio en $1000 \mathrm{ml}$ de medio líquido, se dejaron crecer 21 días en condiciones de luz día, sin agitación. Los cultivos se esterilizaron por filtración a través membranas de $0,20 \mu \mathrm{m}$. Se prepararon diluciones al 50\% y $90 \%$, colocándose 150 vitroplantas por tratamiento, en un diseño completamente al azar, las plántulas provenían de material mantenido en medio de crecimiento con $0,7 \mathrm{mg} / \mathrm{l}$ de BAP. Se evaluó a los 20 días, observándose las plantas muertas y con brotes vivos.

\subsection{Análisis Estadísticos}

Se realizaron pruebas de Análisis Multifactorial para estimar las mejores condiciones de cultivo del hongo en la obtención del filtrado de $C$. gloeosporioides y se realizó análisis de varianza para evaluar la termoestabilidad de los filtrados, utilizando los programas STATGRAPHICS. 5.1 y Zigma plot.

\section{Resultados y discusión}

\subsection{Obtención de Aislamientos monospóricos del hongo}

A partir de tejido infectado se lograron purificar cultivos de hongos, los cuales, con base en las características morfológicas y 
de crecimiento, se identificaron como hongos del género Colletotrichum. Los cultivos in vitro inicialmente mostraron una consistencia algodonosa de color blanco, luego adquirieron una coloración gris, y en algunos casos apareció un crecimiento de masa de esporas de color rosáceo. De acuerdo con las características morfológicas y de crecimiento del hongo, y con los reportes existentes como causal de la antracnosis en cardamomo, se presume la especie como $C$. gloeosporoides según Suseela et al. (1988); Jaramillo \& Herrera (1995); Ravindran (2003) y Thomas \& Suseela (2003). Como resultado de purificación de éste, se obtuvieron cuatro aislamientos monospóricos, los cuales fueron codificados como 171, 172, 241 y 242, donde los dos primeros dígitos corresponden al área de procedencia de los frutos infectados y el último dígito es un número consecutivo de aislamiento.

\subsection{Evaluación de la patogenicidad de aislados monospóricos}

Frutos y plántulas inoculadas con solución de los cuatro aislamientos de esporas desarrollaron sintomatología común de antracnosis en cardamomo. A partir de tejido afectado de los frutos y las plántulas se obtuvo en el laboratorio el crecimiento de colonias de los diferentes aislados. En los frutos infectados se encontró la formación característica de masa de esporas del hongo. Realizar las pruebas de reinfección garantiza la virulencia de los patógenos utilizados en las fermentaciones, lo cual es determinante en la obtención de filtrados con alta actividad tóxica, asegurando su calidad como agente de selección.

\subsection{Determinación de condiciones de fermentación de los cultivos del hongo para la obtención de filtrados crudos}

El análisis multifactorial demostró que la variación en las condiciones de luz, el tiempo de fermentación y el aislamiento, se relaciona con la fitotoxicidad de los filtrados, lo cual no se aplica con el efecto de agitación ( $p=0,2836)$. Para la primera semana de fermentación no se evidenció una respuesta de fitotoxicidad, lo cual 
podría estar asociado a la baja cantidad de sustancias fitotóxicas en el medio. En la Tabla 1 se muestran las interacciones que fueron estadísticamente significativas para el análisis multifactorial.

Tabla 1. AnÁlisis mUltifactorial de LA ASOCIACIÓN ENTRE HOJAS AFECTADAS Y DIFERENTES CONDICIONES DE FERMENTACIÓN

\begin{tabular}{lcccc}
\hline Factor & Suma de cuadrados & GL & $\mathrm{F}$ & $\mathrm{P}$ \\
\hline A: Luz & 2,2478 & 1 & 147,50 & 0,0000 \\
B: Semana & 2,9273 & 2 & 96,04 & 0,0000 \\
C: Aislamiento & 2,0648 & 3 & 45,16 & 0,0000 \\
D: Agitación & 0,0178 & 1 & 1,17 & 0,2836 \\
Interacciones & & & & \\
AB & 0,0900 & 2 & 0,045 & 0,0606 \\
AC & 0,4468 & 3 & 0,148 & 0,0000 \\
Residual & 0,8229 & 54 & 0,015 & \\
\hline Total (Corregido) & 8,997 & 95 & & \\
\hline
\end{tabular}

La interacción con mayor significancia estadística fue luzaislamiento (AC). Se ha demostrado que la producción de toxinas por el patógeno es altamente dependiente de la composición del medio de cultivo, y de las condiciones ambientales que están directamente relacionadas con los procesos fisiológicos de crecimiento y reproducción del patógeno (Urrea et al., 2000; Levin et al., 2007).

Se encontró una mayor actividad fitotóxica de los cultivos que crecieron en condiciones de luz cuando se compara con los mantenidos en oscuridad, este comportamiento fue similar para los 4 aislamientos (Fig. 1). Es de resaltar que aunque las condiciones de luz día generaron mayor actividad fitotóxica, el filtrado del aislamiento 172 en oscuridad presentó mayor fitotoxicidad que los aislamientos 241 y 242 que crecieron en condiciones luz día. Lo anterior demuestra que la producción de fitotoxinas está determinada por las condiciones propias del patógeno e influenciada por condiciones del medio de cultivo y del ambiente. 


\section{Hojas con clorosis}



FIG. 1. INTERACCIÓN DEL EFECTO DE LUZ Y AISLAMIENTO CON RELACIÓN AL NÚMERO DE HOJAS AFECTADAS POR LOS FILTRADOS (DATOS TRANSFORMADOS $y=$ asen $\sqrt{ } x$ )

En cuanto al efecto del tiempo de cultivo del hongo, se encontró que éste influye significativamente en la fitotoxicidad de los filtrados, mostrando una diferencia significativa $(p<0,05)$. En la Fig. 2 se representa la actividad de los filtrados de los aislamientos en cada una de las semanas de fermentación. Se observa un incremento en la fitotoxicidad hasta el día 21 en los cuatro aislamientos. No se encontró una diferencia estadísticamente significativa entre la actividad de los filtrados de 21 y 28 días.

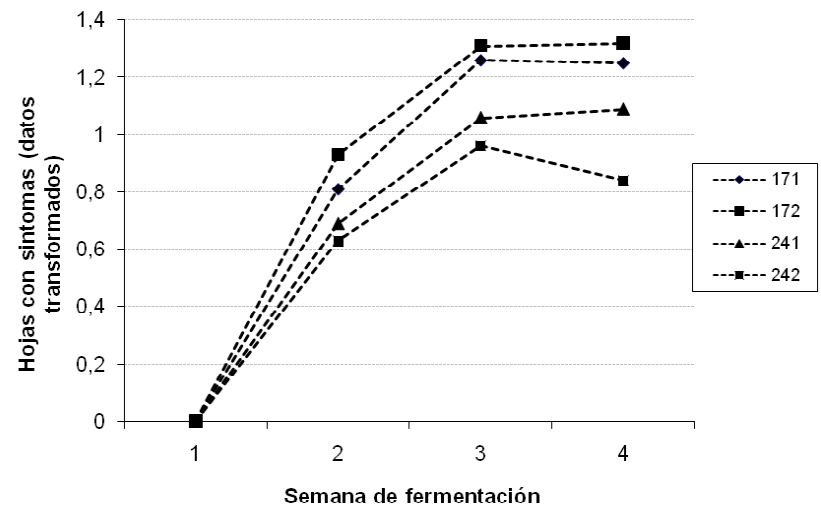

FIG. 2. RELACIÓN DE LA FITOTOXICIDAD DE LOS AISLAMIENTOS EN LAS DIFERENTES SEMANAS DE FERMENTACIÓN (DATOS TRANSFORMADOS $\mathrm{y}=$ asen $\sqrt{ } \mathrm{x}$ ) 
Las Fig. 1 y 2, permiten observar la diferencia en la fitotoxicidad de filtrados que se obtuvieron con cada aislamiento. Se determinó que el aislado 172 produjo filtrados con mayor actividad fitotóxica, en comparación los filtrados de menor actividad fueron los obtenidos con el aislamiento 242. El efecto del aislamiento sobre la fitotoxicidad presentó diferencia estadísticamente significativa $(p<0,05)$, lo cual fue corroborado por el Test de Rangos Múltiples. Estos resultados son similares a los reportados en otros estudios en los cuales se encontró diferencia en la actividad de filtrados cuando se utilizan diferentes aislamientos. Para el caso de Colletorichum se encuentran estudios realizados por Jayansinghe \& Fernando (2000) que evaluaron filtrados de 3 aislados de $C$. acutatum sobre hojas de Hevea y Polyalthia, encontrando que un aislamiento presentaba mayor actividad tóxica. Fernández et al., (2000) evaluaron dos razas de $C$. lindemuthianum en fríjol, y reportaron que en comparación una raza producía mayor actividad o concentración de toxinas en sus filtrados. Existen estudios similares para otros hongos patógenos donde se demuestra la diferencia de actividad fitotóxica cuando se utilizan diferentes aislados tal como, Phythopthora (Urrea, 2000) y Fusarium (Hamed et al., 1996).

En cuanto a la relación de la fitotoxicidad con el tiempo de fermentación del hongo, un estudio realizado por Jayansinghe \& Fernando (2000) evaluaron la fitotoxicidad de los filtrados de Colletotrichum con relación al tiempo, allí emplearon un medio modificado a un volumen de $25 \mathrm{ml}$, el cual fue inoculado con dos discos de $0,7 \mathrm{~cm}$ de micelio, observando que la mayor actividad fue al día 12. Esta relación inóculo-volumen de medio es mayor que la utilizada en el presente estudio, lo cual podría explicar el menor tiempo observado por Jayansinghe \& Fernando.

Estudios realizados con otros hongos patógenos, presentan resultados de mayor patogenicidad resultante después de 21 de crecimiento del hongo, en Phythopthora (Urrea, 2000), se encontró con relación al tiempo de incubación, un incremento en el porcentaje de daño en plántulas de Solanum tuberusum al ser tratados con filtrado del hongo, observándose la afectación característica a 
los 20 y 30 días de fermentación. Considerando los resultados obtenidos y los reportados para estudios anteriores, se concluye que la actividad fitotóxica de los filtrados depende de la capacidad del patógeno de producir toxinas. Sin embargo, las condiciones del medio, el tiempo de fermentación, las condiciones ambientales y la relación cantidad de patógeno-volumen del medio, tienen un importante efecto sobre la cantidad de sustancias tóxicas que el patógeno produce en el filtrado.

\subsection{Evidencia de fitotoxicidad de los filtrados en hojas y frutos}

La actividad fitotóxica de los filtrados se evidenció por la aparición de manchas de colores con tonalidades de café: entre pardo claro a café oscuro, que son similares a las manchas producidas por el hongo en el tejido foliar in vivo. Este tipo de clorosis puede afectar todo el tejido expuesto, generando en algunos casos necrosis total. En la Fig. 3 se compara las manchas producidas por la acción del hongo, de los filtrados en hojas y frutos.

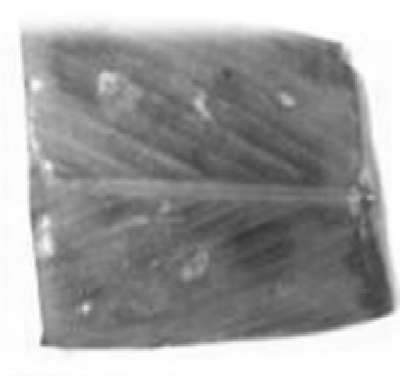

a)



b)

Fig. 3. Efecto del Colletotrichum y de los filtrados del hongo sobre hojas CARDAMOMO, A) MANCHAS EN TEJIDO FOLIAR PRODUCIDAS POR EL FLLTRADO Y B) MANCHAS EN TEJIDO FOLIAR PRODUCIDAS POR EL HONGO

La inducción de síntomas completos o parciales de la enfermedad en tejidos del hospedero, es fundamental en la determinación de la presencia de sustancias fitotóxicas en los filtrados (Jayansakar, 
1999). Esta aproximación permite realizar estimaciones semicuantitativas de la actividad biológica de los filtrados (Strobel, 1982).

Son numerosos los reportes referentes a las especies de Colletotrichum, en donde se demuestra que en los filtrados, se encuentran metabolitos fitotóxicos generados por el hongo, los cuales inducen en las plantas hospederas síntomas similares a los producidos por los hongos. Yoshida et al., (2000) demostraron la presencia de toxinas no-hospedero específicas en los filtrados del hongo C. dematium que causaban lesiones necróticas en hojas de diferentes plantas como, mora, rábano, durazno, entre otros. Jayasinghe \& Fernando (2000) demostraron la actividad fitotóxica del cultivo líquido de C. acutatum al inducir sintomatología características de antracnosis en hojas de caucho y la presencia de toxinas no-hospedero específicas al inducir síntomas en hojas de diferentes plantas como; Cocoa, Ficus, Oryza, entre otras. Otros estudios para las especies de Colletotrichum son los realizados por; Buitrago \& Pacheco (1991); Ohra, (1995); Nyange et al., (1997); Fernández et al., (2000), Garcia \& Pajon, (2003); Mohanraj, (2003); Amusa, (2006); Alleyne \& O'garro (2008) y Theerthagiri, (2008).

\subsection{Evaluación de la termoestabilidad de los filltrados del hongo}

Se demostró que la actividad fitotóxica del filtrado fue similar entre temperaturas de $25^{\circ} \mathrm{C}$ a $120^{\circ} \mathrm{C}$, al no encontrarse diferencia estadísticamente significativa de la fitotoxicidad de los filtrados al ser sometidos a diferentes temperaturas $(p=0,79)$, ver Tabla 2 .

TABLA 2. ANÁlisis de VARIANZA DEL EFECTO dE LAS DIFERENTES TEMPERATURAS SOBRE LA FITOTOXICIDAD DE LOS FILTRADOS DEL HONGO

\begin{tabular}{lcccc}
\hline Efecto & Suma de cuadrados & GL & F & P \\
\hline Entre grupos & 0,070135 & 3 & 0,35 & 0,7921 \\
Dentro & 5,13422 & 76 & & \\
\hline Total (Corregido) & 5,82628 & 79 & & \\
\hline
\end{tabular}


En la Fig. 4 se observa que la fitotoxicidad de los diferentes filtrados se conservó al someterlos a temperaturas superiores de $40^{\circ} \mathrm{C}$ hasta los $100^{\circ} \mathrm{C}$, para $120^{\circ} \mathrm{C}$ a $20 \mathrm{lb}$ de presión, se encontró una leve disminución de la fitotoxicidad. Resultados semejantes para Colletotrichum han sido registrados por Jayansinghe \& Fernando (2000), quienes evaluaron temperaturas de $40^{\circ} \mathrm{C}, 50^{\circ} \mathrm{C}, 60^{\circ} \mathrm{C}, 70^{\circ} \mathrm{C}$, $80^{\circ} \mathrm{C}, 90^{\circ} \mathrm{C}, 100^{\circ} \mathrm{C}$ y $120^{\circ} \mathrm{C}$ y reportaron termoestabilidad de las filtrados de C. acutatum, al encontrar actividad tóxica de estos, sobre hojas de Hevea y Polyalthia, presentándose una leve disminución de la fitotoxicidad de los filtrados expuestos a esterilización a $120^{\circ} \mathrm{C}$ y a una presión de 15 libras por 15 minutos, la termoestabilidad de los filtrados de las fermentaciones de Colletotrichum ha sido reportada igualmente por Mathew et al. (2009). Estudios realizados para diferentes especies de hongos presentan un comportamiento semejante, en el caso de Pytohothora, (Urrea, 2000), se encontró que sus filtrados conservaban su actividad al ser expuestos a temperaturas de $120^{\circ} \mathrm{C}$, lo anterior ha sido demostrado de igual manera para Ustilago y Alternaria (Gómez, 1996; Dita, 1998) reportados por Urrea, 2000) y para Fusarium (Hamed, 1996).

Hojas con síntomas

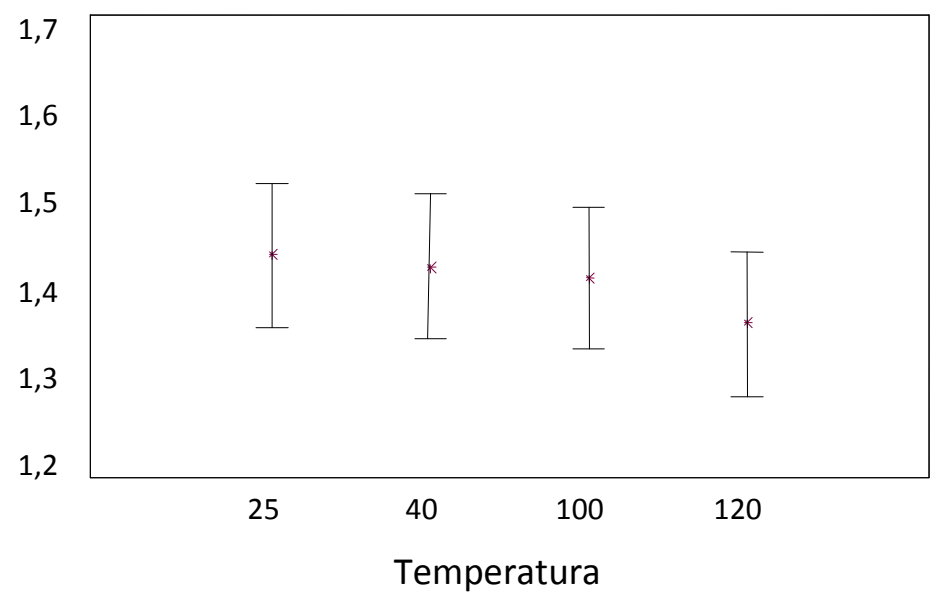

Fig. 4. Comparación del EFECTO dE LA TEMPERATURA SOBRE LA FITOTOXICIDAD DE LOS FILTRAdOS. Se PRESENTAN LOS PROMEDIOS Y LOS INTERVALOS DE CONFIANZA DEL 95\% 
En los filtrados crudos se encuentran diferentes tipos de compuestos asociados a la fitotoxicidad. Entre ellos están los de tipo proteico, como son las enzimas que degradan las paredes vegetales, o metabolitos secundarios que actúan en el proceso enfermedad de la planta; Buitrago \& Pacheco (1991); Ohra, (1995); Nyange et al., (1997); Fernández et al., (2000), Garcia \& Pajon, (2003); Mohanraj, (2003); Amusa, (2006), Alleyne \& O`garro (2008); Gangadevi, \& Muthumary, (2008) y Theerthagiri, (2008). La termoestabilidad de los filtrados puede ser explicada debido a la alta estabilidad molecular de los metabolitos tóxicos, lo cual sugiere que al aumentar la temperatura en los filtrados se puede afectar moléculas involucradas en la patología de la planta, pero se mantienen algunas necesarias en el desarrollo de la enfermedad. La termoestabilidad de las toxinas es una forma de favorecer la patogénesis.

\subsection{Evidencias de Fitotoxicidad de los filtrados crudos en vitroplantas de cardamomo}

Se demostró la actividad fitotóxica de los filtrados sobre vitroplantas de cardamomo. Estás desarrollaron inicialmente una clorosis foliar, la cual fue tomando un color café claro, posteriormente, se afectaron los tallos, finalizando el proceso con la muerte de la vitroplanta. La clorosis observada parece reducir la clorofila de la planta, lo cual sería uno de los efectos fisiológicos de las toxinas sobre las plántulas. No se han encontrado reportes de estudios donde se evalué del efecto del filtrado de Colletotrichum sobre vitroplantas.

La actividad biológica de los filtrados del hongo se ha evaluado sobre: células y protoplastos de Cofee (Nyange et al., 1997), formación de callos de Phaseolus (Fernández et al., 2000), Solanum (Giraldo \& Martínez, 1998), Sugarcane (Mohanraj, 2003), en hojas de diferentes géneros de hospederos (Buitrago \& Pacheco, 1991; Ohra, 1995; Yoshida et al., 2000; Amusa, 2006; Alleyne \& O'garro, 2008). Al evidenciarse el efecto fitotóxico del filtrado sobre la vitroplanta, se demuestra que el filtrado crudo puede utilizarse 
como agente de selección sobre plántulas. En la actualidad, existe gran interés en desarrollar técnicas que permitan de una manera rápida determinar la susceptibilidad o resistencia de las plantas a los patógenos. Se considera que el uso de filtrados crudos del patógeno puede ser una herramienta elemental a utilizar en este proceso de selección de plántulas tanto a nivel in vitro e in vivo.

\section{Conclusiones}

Con el desarrollo del presente estudio fue posible demostrar la actividad fitotóxica de las filtrados crudos de Colletotrichum gloeosporiodes sobre tejidos y vitroplantas de cardamomo, se demostró que la actividad fitotóxica de los filtrados depende de la capacidad del patógeno de producir toxinas. Sin embargo, las condiciones del medio, el tiempo de fermentación, las condiciones ambientales y la relación cantidad de patógeno - volumen del medio, tienen un importante efecto sobre la cantidad de sustancias tóxicas que el patógeno produce en él, adicionalmente se demostró la termoestabilidad de los fitotóxicos presentes en los filtrados de Colletotrichum.

\section{REFERENCIAS}

Alleyne, A., O'garro L. (2008); Host selectivity of a 40kDa phytotoxic extract from Colletotrichum gloeosporioides (Phyllachoraceae) on yam Dioscorea alata (Dioscoreace), Caribbean Journal of Science, 44(1), 1-12.

Amusa, N.A., (2001); Screening of cassava and yam cultivars for resistance to antracnose using toxic metabolites of Colletotrichum species, Mycopathologia, 150(3), 137-142.

Amusa, N.A. (2006); Microbially produced phytotoxins in disease management, African Journal of Biotechnology, 5(5), 405-414.

Bailey, J.A., Jeger, M.J. (1992); Colleotricum: Biology: Pathology and Control, British Society for Plant Pathology CAB Internacional.

Ballio, A., Bottalico, A., Buonocore, V., Carilli, A., DI Vittorio, V., Graniti, A., (1969); Production and isolation of aspergillomarasmin B (lycomarasmic acid) from cultures of Colletotrichum gloeosporioides Penz (Gloeosporium olivarum Alm.), Phytopthologia Mediterranea, 8, 187-196. 
Buitrago, A.R., Paheco, M., (1991); Efecto del filtrado de Colletotrichum sp. En la expresión de síntomas de mancha mantecosa en cafetos cultivados in vitro, Cenicafé, 42(1).

Duke, E., Gohbara, M., Paul, R., Duke, M., (1992); Colletotrichin causes rapid membrane damage to plant cells, J. Phytopathol., 134, 289-30.

Fernandez, M.T., Fernanadez, M., Centeno, M.L., Cañal, M.J., Rodríguez, R., (2000); Reaction of common bean callus to culture filtrate of Colletotrichum lindemuthianum differences in the composition and toxic activity of fungal culture filtrates, Plant Cell, Tissue and Organ Culture, 61, 41-49.

Gangadevi, V., Muthumary, J., (2008); Isolation of Colletotrichum gloeosporioides, a novel endophytic taxol-producing fungus from the leaves of a medicinal plant, Justicia gendarussa Mycologia balcanica, 5, 1-4.

García-Pajón, C.M., Collado, I.G., (2003); Secondary metabolites isolated from Colletotrichum species, Nat. Prod. Rep., 20.

Gohbara, M., Hyeon, S.B., SuzukI, A., Tamura, S., (1976); Isolation and structure elucidation of colletopyrona from Colletotrichum nicotianae, Agriculture Biology Chemistry, 40, 1453-1455.

Gohbara, M., Kosuge, Y., Yamasaky, N., (1978); Isolation structure and biologycal activities of colletotrichins fitotoxic susbtans from Colletotrichum nicotianae, Agriculture Biology Chemistry, 42, 1037-1043.

Jaramillo, J.W., Herrera, J.A., (1995); Enfermedades del Cardamomo (Elettaria cardamomum) (l) maton) en el municipio de Jericó, departamento de Antioquia, Tesis Universidad Nacional de Colombia, sede Medellín.

Jayasankar, S., Litz, R.E., (1998); Characterization of embriogenic mango cultures selected for resistance to Colletotrichum gloeosporioides culture filtrate an phytotoxin, Theoric Applied Genetic, 96, 823-831.

Jayasankar, S., Litz, R.E., Gray, D.J., Moon P.A., (1999); Responses of Embryogenic mango cultures and seedling bioassays to a partially purified phytotoxin produce by a mango leaf of Colletotrichum gloeosporioides Penz, In Vitro Cell Developed Biology Plant, 475-479.

Jayasinghe, C.K., Fernando, T.H., (2000); Toxic activity from liquid culture of Colletotrichum acutatum, Mycopathologia, 152, 97-101.

Levin, L., Ramos, A., Parisi, M., Gally, M., (2007); Screening of Colletotrichum (Ascomycota) isolates, causal agents of Soybean Anthracnose, for Laccase production, Bol. Soc. Argent. Bot. 42(1-2), 71-77. 
Mathew, A., Wolf-rainer, A., Robert, A., Peter, H., Gerhard, W., Step, H., (2009); Secondary metabolite profile and phytotoxic activity of genetically distinct forms of Colletotrichum gloeosporioides from yam (Dioscorea spp.), Mycological Research, 113(1), 130-140.

Mohanraj, D., Padmanaban, P., Karunakaran, M., (2003); Effect of Phytotoxin of Colletotrichum falcatum Went. (Physalospora tucumanensis) on Sugarcane in Tissue Culture, Acta Phytopathologica et Entomologica Hungarica, 38(1-2), 21-28.

Murashige, T., Skoog, F., (1962); A revised medium for rapid growth and bioassays with tobacco tissue cultures, Physiolgy Plant, 15, 473-497.

Nyange, N.E., Williamson, B., Lyon, G., Mcnicol, D.R., Connolly, J.T., (1997); Responses of cells and protoplasts of Coffea arabica genotypes to partially purified culture filtrates produced by Colletotrichum kahawae, Plant cell Reports 16, 763-769.

Ohra, J., Morita, K., (1995); Production of phytotoxic metabolite, by the fungus Colletotrichum gloeosporioides, Biosciences Biotechnology Biochemistry, 59(1), 113-114.

Osorio, M., (2001); Caracterización morfológica de Colletotrichum gloeosporioides (Penz) Penz \& Sacc de las zonas productoras de tomate de árbol (Solanum betacea) en el departamento de Antioquia, Tesis para obtar título de Ingeniera Agrónoma, Universidad Nacional de Colombia Sede Medellín.

Ravindran, P., (2003); Cardamom: The Genus Elettaria, En Medicinal and Aromatic Plants-industrial Profiles, Ed. New York Taylor \& Francis.

Strobel, G., (1982); Phytotoxins, Annual Review of Biochemistry, 51, 309333.

Suseela, R., Thomas, J., Naidu, R., (1988); Anthranose - a new disease of small cardamom, Current Science, 57(24), 1346-1347.

Svabova, L., Lebeda, A., (2005); In Vitro Selection for Improved Plant Resistance to Toxin-Producing Pathogens, J Phytopathology, 153, 52-64.

Tamayo, A.C., (2003); Caracterización molecular de materiales seleccionados de cardamomo Eletteria cardamomum L. (Matón) utilizando marcadores AFLP, Tesis de Maestría en Biotecnología, Universidad Nacional de Colombia.

Thomas, J., Suseela, R., (2003); Cardamom: The Genus Elettaria, En Medicinal and Aromatic Plants-industrial Profiles, Ed New York Taylor \& Francis. 
Theerthagiri, A., Ramanujam, B., Thiruvengadam, R., Gandhi, K., Manikam, R., Govindasamy, S., (2008); Production of cell wall degrading enzymes and toxins by colletotrichum capsici and alternaria alternata causing fruit rot of chillies, Journal of plant protection research, 48(4).

Urrea, A., Goméz, R., Orellana, P., Herrera, L., Veitia, N., Alvarado, Y., (2000); Estudio de parámetros para la selección in vitro empleando medios derivados de phytophthora infestan (Mont). de Bary para inducir respuesta de resistencia en papa (Solanum tuberosum L), Actualidades Biológicas, 22(72), 5-15.

Van den Bulk, R.W., (1991); Aplication of cell and tissue culture and in vitro selection for disease resistance breeding a review, Euphytica, 56, 269285 .

Yoder, O.C., Turgeon, G., (1985); Molecular analysis of the plant fungus interaction, Molecular Genetics of filamentous fungi, New York, Alan Liss Inc., 383-403.

Yoder, O.C., (1998); A Holistic view of the plant/fungal interaction based on host-specific toxin studies, Molecular Genetics of Host-specific toxins in Plant Disease, Dordrecht, Kluwer Academic Publishers, 3-15.

Yoshida, S., Hiradate, S., Fujii, Y., Shirata, A., (2000); Colletotrichum dematium produces phytotoxins in anthracnose lesions of mulberry leaves, Phytopathology, 90, 285-291. 